\section{Autoantikörper gegen Annexin A5}

\author{
W. Stöcker \\ Euroimmun Medizinische Labordiagnostika AG, Lübeck, \\ Deutschland
}

Synonym(e) Annexin-A5-Antikörper; Anti-Annexin-A5Antikörper

Englischer Begriff Annexin A5 antibodies; anti-annexin A5 antibodies

Funktion - Pathophysiologie Annexin A5 (ursprüngliche Bezeichnungen Annexin-V oder ,placental anticoagulant protein I“) ist ein starker Gerinnungshemmer, es wird vom Trophoblasten der Plazenta, von $>$ Thrombozyten und von Endothelzellen exprimiert. Indem es mit anionischen Phospholipiden Komplexe bildet, behindert es deren gerinnungsauslösende Wirkung: Auf der Außenseite der Plasmamembran eukaryontischer Zellen befinden sich normalerweise keine negativ geladenen Phospholipide. Unter bestimmten Bedingungen, wie zum Beispiel der Thrombozytenaktivierung ( $\triangleright$ Thrombozytenaggregation und -aktivierung) oder der Apoptose, gelangt jedoch das anionische Phospholipid Phosphatidylserin an die Außenseite der Plasmamembran. Aufgrund seiner hohen, calciumabhängigen Affinität zu Phosphatidylserin bindet sich Annexin A5 an die Phosphatidylserin-haltigen Membranbereiche und bildet einen zweidimensionalen kristallinen Proteolipidkomplex aus, wodurch Phospholipid-abhängige Koagulationsreaktionen, wie die Prothrombinaktivierung, inhibiert werden.

Antikörper gegen Annexin A5 stören die Ausbildung der kristallinen Struktur und führen zu einer Destabilisierung des
Gerinnungssystems. Möglicherweise hängt die Thromboseinduzierende Wirkung bestimmter $\triangleright$ Autoantikörper gegen Phospholipide ursächlich mit der Verdrängung von Annexin A5 zusammen.

Untersuchungsmaterial Serum, Plasma.

Probenstabilität Autoantikörper sind bei $+4{ }^{\circ} \mathrm{C}$ bis $\mathrm{zu}$ 2 Wochen lang beständig, bei $-20^{\circ} \mathrm{C}$ über Monate und Jahre hinweg.

Analytik Enzyme-linked Immunosorbentassay mit rekombinantem Annexin A5. Tomer et al. (2007) beschreiben einen Flow-cytometrischen „Annexin-A5-Kompetitionstest“.

Referenzbereich - Erwachsene Negativ.

Referenzbereich - Kinder Negativ.

Indikation Antiphospholipid-Syndrom. In Zusammenhang mit Schwangerschaften erhöhtes arterielles sowie venöses Thromboserisiko, mögliche intrauterine Schädigung des ungeborenen Kindes.

\section{Literatur}

Rand JH, XX W, Lapinski R, van Heerde WL, Reutelingsperger CP, Chen PP, Ortel TL (2004) Detection of antibody-mediated reduction of annexin A5 anticoagulant activity in plasmas of patients with the antiphospholipid syndrome. Blood 104:2783-2790

Tomer A, Bar-Lev S, Fleisher S, Shenkman B, Friger M, Abu-Shakra M (2007) Antiphospholipid antibody syndrome: the flow cytometric annexin A5 competition assay as a diagnostic tool. $\mathrm{Br} \mathrm{J}$ Haematol 139:113-120 